\title{
Mechanical properties of composite coatings of chromium and nanodiamonds on aluminum
}

\author{
Nelly Gidikova ${ }^{1}$, Maciej Sulowski ${ }^{2}$, Marcin Madej $^{2}$, Radoslav Valov ${ }^{1, *}$ and Vladimir \\ Petkov $^{1}$ \\ ${ }^{1}$ Institute of Metal Science, Equipment and Technologies with Hydro Aero Dynamics Center "Acad. \\ Angel Balevski" at Bulgarian Academy of Sciences, 67 Shipchenski prohod, 1574 Sofia, Bulgaria \\ ${ }^{2}$ AGH University of Science and Technology, Al. Mickiewicza 30, 30-059 Krakow, Poland
}

\begin{abstract}
Aluminum offers engineers weight saving advantages in their product design. However, aluminum has poor wear and friction properties. In addition, the surface oxide layer of this chemically active metal, which gives it the corrosion resistance, makes it a very difficult metal to plate [1]. Specific pre-treatment must be applied to remove the oxide layer from the aluminum surface. The nanodiamond particles additionally facilitates the process of chromium deposition. The object of this study is to evaluate the impact of nanodiamonds on the mechanical properties of the chromium coating plated on
\end{abstract}

\section{Introduction}

The aluminum has a lot of advantages in the design of engineering products because of its low weight. On the other hand it is relatively soft metal which means poor wear resistance and friction coefficient. New applications are possible when the light weight of aluminum is combined with the durability of the hard chrome.

The most widely commercially used now-a-days process for preparing an aluminum surface for plating is the zinc immersion process [2]. In this process a thin and adherent film of metallic zinc or alloy of zinc replaces the aluminum oxide film. The zinc provides a surface which is more readily plated with other metals than the aluminum. Not all metals, however, may then be simply deposited directly on the zinc surface.

The electrochemical chromium coatings have a wide practical application. They increase the hardness and the wear resistance of the matrix material and possess increased corrosion resistance. The modification of the chromium galvanic coatings with nanodiamond particles (ND) additionally increases these chemical and mechanical properties.

The main goal of this study is to investigate the influence of the ND on the readiness of chromium to be plated on the aluminum surface, the thickness and the continuity of the coating, the microhardness and wear resistance of the composite material comprised of electrolytic chromium coatings with nanodiamond particles and aluminum matrix material.

\footnotetext{
*Corresponding author: radoslav.valov@gmail.com
} 


\section{Experimental}

The research conducted in this study is directed to evaluate the mechanical properties of composite chromium coating modified with nanodiamond particles on samples of aluminum alloy (dural AC 2017). The chromium was deposited on the surface of the aluminum items by electrolytic process with the traditional acidic electrolyte containing $\mathrm{CrO}_{3}-220 \mathrm{~g} / \mathrm{l}$ and $\mathrm{H}_{2} \mathrm{SO}_{4}-2.2 \mathrm{~g} / \mathrm{l}$. The parameters of the electrolytic process were: current density $-45 \mathrm{~A} / \mathrm{dm}^{2}$; duration of the process $-45 \mathrm{~min}$ and temperature of the electrolyte $50^{\circ} \mathrm{C}$. The diamond nanoparticles were added to the electrolyte as an aqueous suspension. Their concentration was 5, 10 and $25 \mathrm{~g} / \mathrm{l}$. The nanodiamond particles were produced by detonation synthesis [3].

The thickness of the coatings was determined by light microscopy. The microhardness tests were carried out according to Vickers standard at minimum 10 points. The applied load was $10 \mathrm{~g}$. The dry friction wear resistance was studied by the pin-on-plate test unit (fig. 1). During the test a rectangular $15 \times 5 \times 10 \mathrm{~mm}$ wear sample (1) was mounted in a sample holder (4) equipped with a hemispherical insert (3) ensuring proper contact between the test sample and a steel ring (2), heat treated to $55 \mathrm{HRC}$, which was rotated at a constant speed of $136 \mathrm{rpm}$. The wear surface of the sample was perpendicular to the loading direction. Double lever system was used to force the sample towards the ring at $157 \mathrm{~N} \pm$ $1 \%$ and $307 \mathrm{~N}$.

The loss of sample mass was measured after a sliding distance of $500 \mathrm{~m}$.

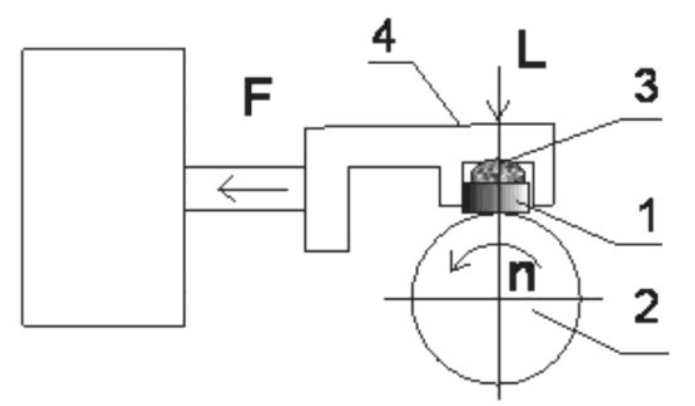

Fig. 1. Schematic view of a block-on-ring test unit

\section{Results and discussion}

Figures 2, 3 and 4 show the scanning electron image of coatings obtained from electrolytes with different concentrations of diamond nanoparticles. 


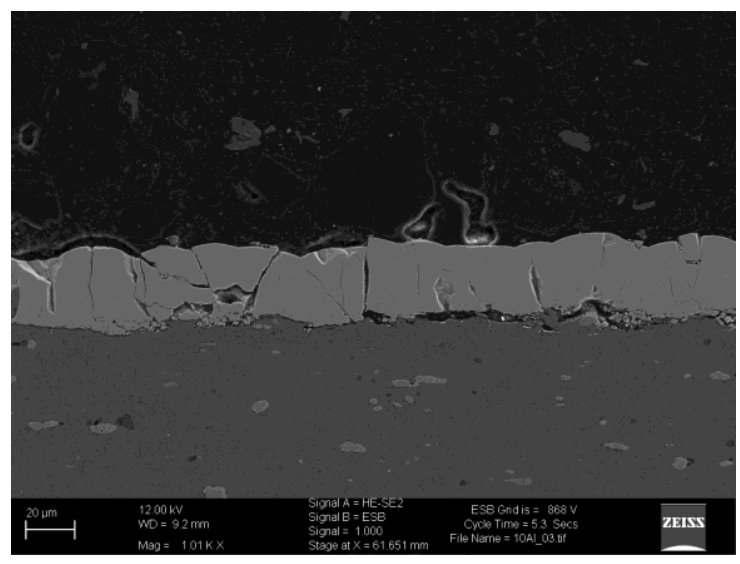

Fig. 2. SEM image of composite coating on aluminum, concentration of nanodiamonds $-5 \mathrm{~g} / \mathrm{l}$

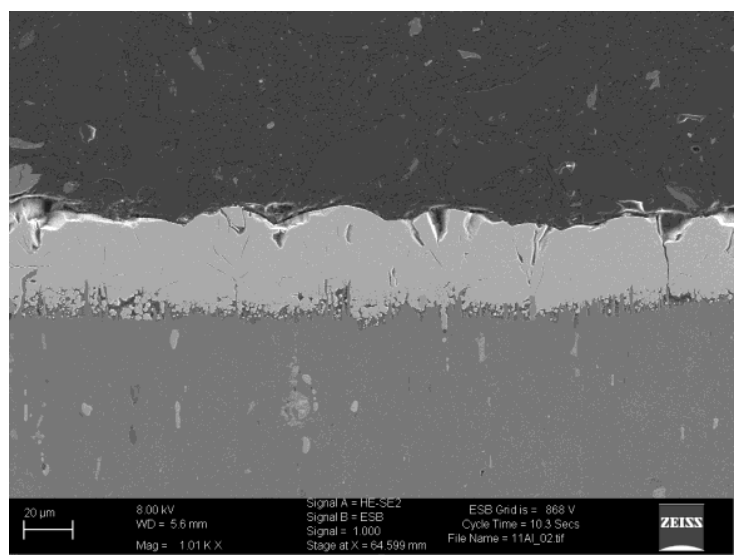

Fig. 3. SEM image of composite coating on aluminum, concentration of nanodiamonds $-10 \mathrm{~g} / \mathrm{l}$

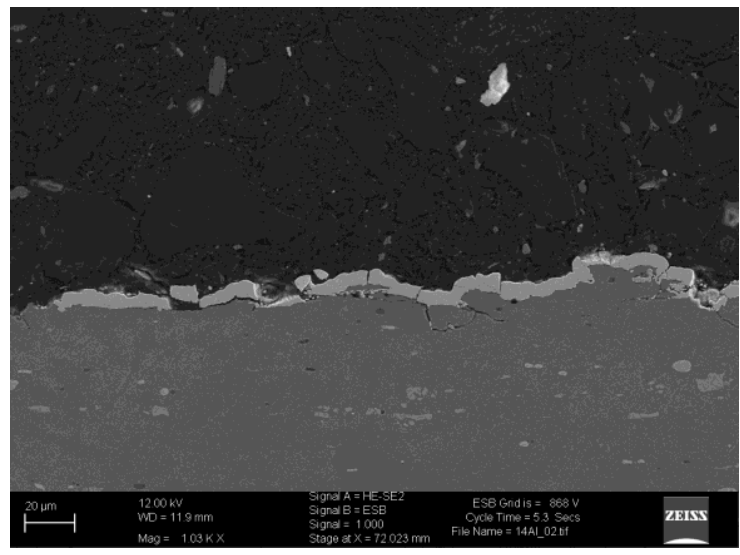

Fig. 4. SEM image of composite coating on aluminum, concentration of nanodiamonds $-25 \mathrm{~g} / 1$

It was found out that the yield of chromium on steel and the thickness of the coating is increased with the increase of the concentration of the diamond nanoparticles [2]. It is not the same with the chromium coating on aluminum and especially on this alloy. It is clearly seen from the figures that the best coating is achieved from electrolyte with concentration 
of nanodiamonds $10 \mathrm{~g} / \mathrm{l}$ (fig.2). The same tendency is observed when testing the mechanical properties of the coating. The microhardness is the biggest at concentration of nanodiamonds $10 \mathrm{~g} / \mathrm{l}$ (fig. 5). It goes from $260 \mathrm{~kg} / \mathrm{mm}^{2}(5 \mathrm{~g} / \mathrm{l})$ to $283 \mathrm{~kg} / \mathrm{mm}^{2}(10 \mathrm{~g} / \mathrm{l})$ and falls down to $230 \mathrm{~kg} / \mathrm{mm}^{2}(25 \mathrm{~g} / \mathrm{l})$. The matrix under the coating is also with increased microhardness $\left(140-200 \mathrm{~kg} / \mathrm{mm}^{2}\right)$ compared to $90-100 \mathrm{~kg} / \mathrm{mm}^{2}$ for the uncoated aluminum alloy.

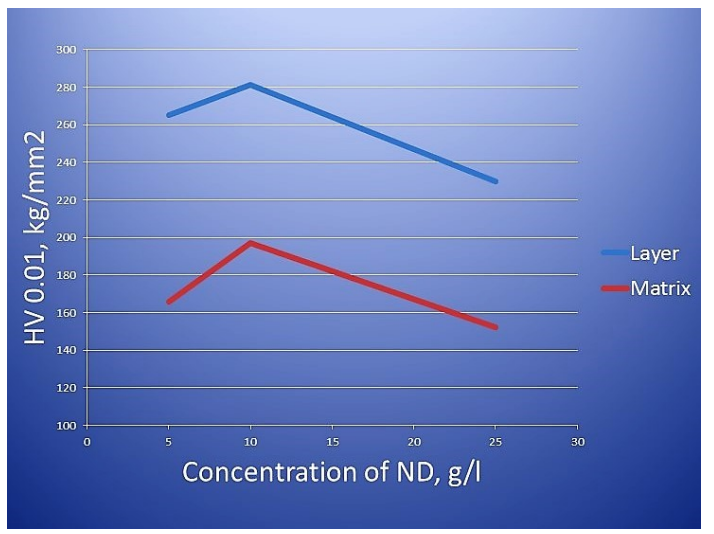

Fig. 5. Microhardness of the composite coating and the aluminum matrix at different concentrations of nanodiamonds

The wear resistance and the friction coefficient of the composite coating have similar behavior as the thickness of the coating at different concentrations of nanodiamonds (fig. 6 and 7). The best results are obtained at concentration of nanodiamonds in the electrolyte 10 $\mathrm{g} / \mathrm{l}$.

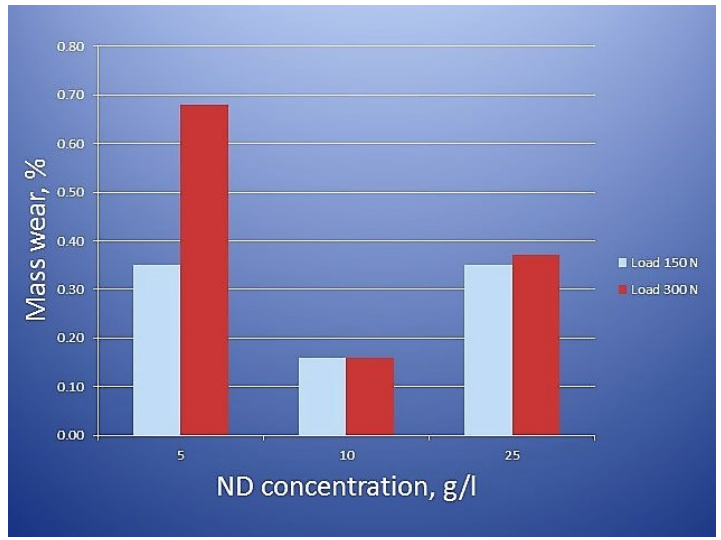

Fig. 6. Wear resistance of the composite coating expressed as mass wear at different concentrations of nanodiamonds 


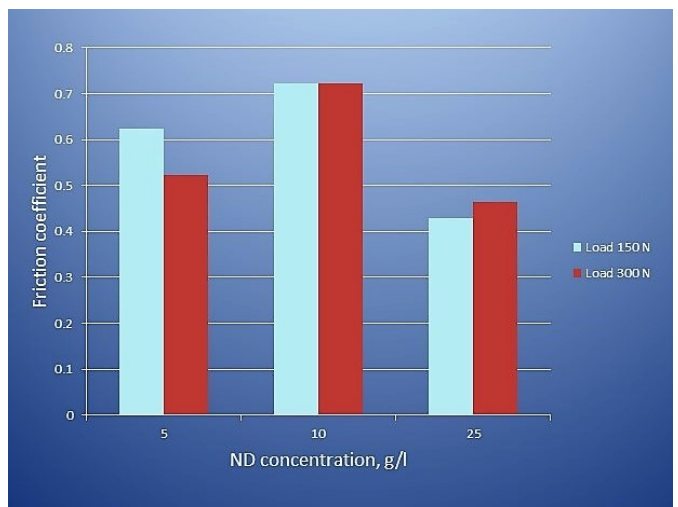

Fig. 7. Friction coefficient of the composite coating at different concentrations of nanodiamonds

The surface topography of the samples prepared at concentrations of nanodiamonds 5 and $10 \mathrm{~g} / \mathrm{l}$ after the wear tests at sliding distance $500 \mathrm{~m}$ are shown in figures 8 and 9 . The applied load is $150 \mathrm{~N}$. Two types of wear mechanism can be seen, abrasive and corrosive wear. The dominate mechanism is corrosive wear. There are oxide regions on the surface after the tribological test.

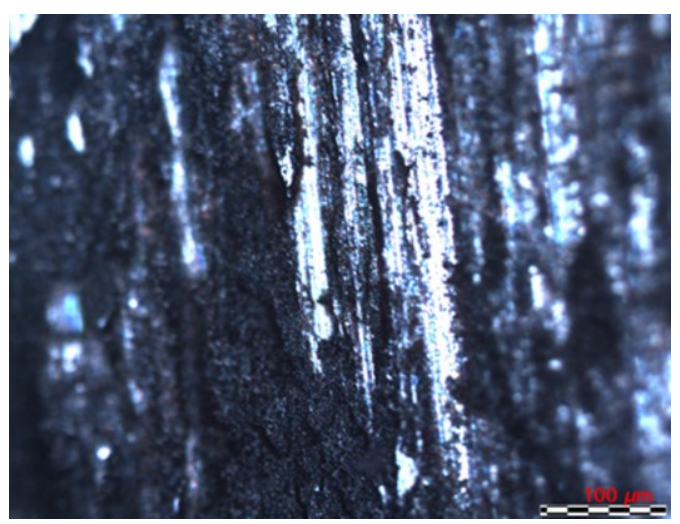

Fig. 8. Surface topography of sample with $5 \mathrm{~g} / \mathrm{l} \mathrm{ND}$ after the wear test. Applied load $150 \mathrm{~N}$ and sliding distance $500 \mathrm{~m}$.

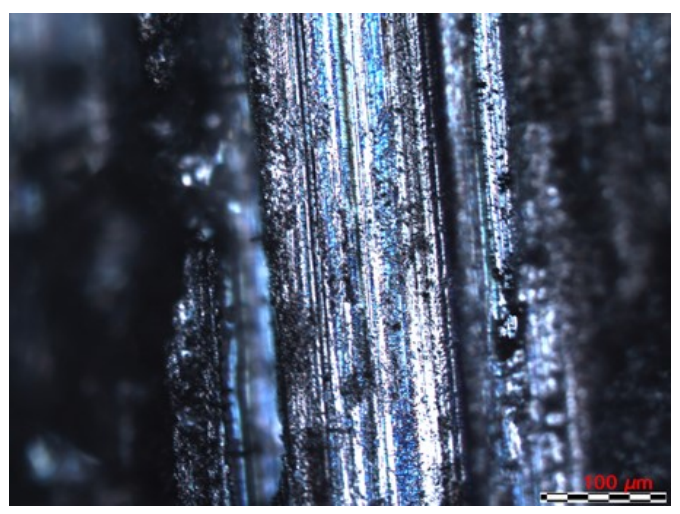

Fig. 9. Surface topography of sample with $10 \mathrm{~g} / \mathrm{l} \mathrm{ND}$ after the wear test. Applied load $150 \mathrm{~N}$ and sliding distance $500 \mathrm{~m}$. 
The typical wear mechanism of the sample with $25 \mathrm{~g} / \mathrm{l} \mathrm{ND}$ after the wear test at sliding distance $500 \mathrm{~m}$ is abrasive wear, but there is small amount of adhesive wear (fig. 10).

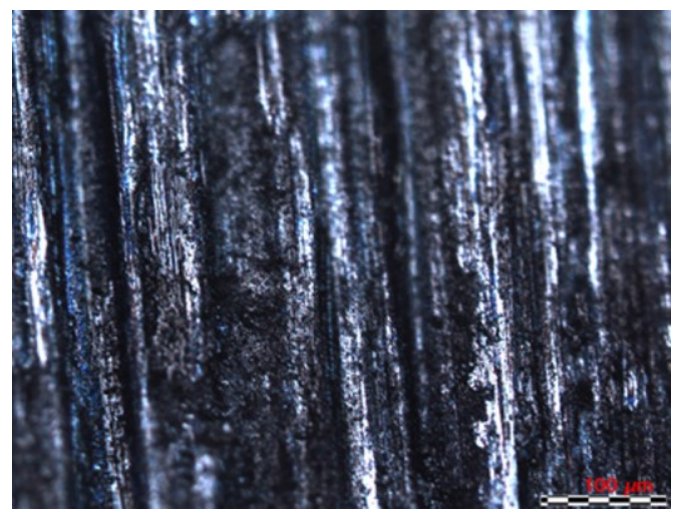

Fig. 10. Surface topography of sample with $25 \mathrm{~g} / \mathrm{l} \mathrm{ND}$ after the wear test. Applied load $150 \mathrm{~N}$ and sliding distance $500 \mathrm{~m}$.

\section{Conclusions}

The presence of nanodiamond particles in the electrolyte facilitates the process of chromium deposition on aluminum items.

The chromium coating adheres very well on the substrate aluminum with thickness of about $20 \mu \mathrm{m}$.

The chromium coating increases the wear resistance and improves the friction of the aluminum products.

Two types of wear mechanism can be seen, abrasive and corrosive wear. The dominate mechanism is corrosive wear. There are oxide regions on the surface after the tribological test.

The financial support of the Fund "Scientific Researches" at the Ministry of Education and Science, Contract No DN 07/8/15.12.2016 is gratefully acknowledged.

\section{References}

1. U.S.Chrome Inc. Hard Chrome Plating, http://www.uschrome.com/chromium-on aluminum.

2. P.J. Topelian, US Pat 2, 847, 371, Chromium Plating on Aluminum (2014)

3. G.K. Burkat, V.Y.Dolmatov, E.Osawa, E.A.Orlova, J.of Superhard Mater. 32, 2, 98 $111(2010)$ 